\title{
Triadic Modal and Pentatonic Patterns in Rock Music
}

\author{
NICOLE BIAMONTE
}

\begin{abstract}
The pitch syntax of mainstream rock music comprises a variety of tonal, modal, blues-based and chromatic elements. Traditional constructs of scale-degree theory and harmonic functionality, while originally pertaining to art music, can be usefully modified to address elements of rock music that do not conform to tonal norms, particularly when these elements are considered in conjunction with other musical parameters such as rhythm, hypermeter, texture, consonance, and contour. This study examines the context and function of some harmonic structures unique to rock music that cannot be interpreted in conventional tonal terms: double-plagal and Aeolian progressions, and triad-doubled scale systems.
\end{abstract}

Keywords: analysis, rock music, harmony, phrase structure, modes, modal, pentatonic

$\mathrm{W}$ HILE SURFACE-LEVEL PITCH SYNTAX AND BEHAVIOR in vernacular musics may differ from those of the common-practice tradition, many underlying organizational principles do not, among them pitch centricity and hierarchy, relative consonance and dissonance, and phrase structure and function. Analytical frameworks developed to understand these principles can be profitably adapted to address modal, pentatonic, and blues-based structures in rock and other musics. ${ }^{1}$ This study investigates the harmonic and phrase functions of selected pitch structures unique to rock that comprise the basic material of a significant body of songs, and that do not fit comfortably into the conventional paradigm of major-minor tonality: double-plagal and Aeolian progressions, and triaddoubled pentatonic and hexatonic modal systems. The repertory under consideration is the "classic-rock" canon established by radio programming, comprising a core of North American and British mainstream rock, pop-rock, hard rock, and progressive rock from the late 1960s to the 1990s—although the structures examined in this study are also readily found in later music and in related genres such as folk-rock, soft rock, heavy metal, grunge rock, and various subgenres of dance music. Several hundred classic-rock songs were surveyed.

Admittedly, this essay's analytical focus on harmonic structures adds to the problematic emphasis on pitch-based analysis to date (not just in popular-music scholarship) and the comparative neglect of other important parameters such as timbre, texture, and sound production, for which analytical tools and methodologies are still being developed. However, the chord

Earlier versions of this paper were presented at meetings of Music Theory Midwest (Bowling Green State University, 2008) and the Society for Music Theory (Nashville, 2008). Thanks are due to Walter Everett, John Covach, Mark Spicer, Jerry Cain, and the anonymous referees for helpful comments at various stages of this project. Recorded versions (of varying quality) of all songs discussed in this article are available on YouTube at www.youtube.com.

I A survey of tonal systems in rock music, comprising major, minor, modal, mixed, triad-doubled pentatonic, and chromatic systems, is given in Everett (2004). pattern is typically the most consistent element among versions of a song by different artists, along with a generalized rhythmic and melodic profile, the specific details of which might vary between versions, performances, or even verses. The aspects of timbre and texture that render specific recordings of songs so immediately recognizable are essential components of the received texts, and often of the performers' idiolects in general, but are not essential components of the songs as compositional texts. I make this claim not to argue for the primacy of the pitch domain in popular music, but rather to justify the essentially formalist orientation of this study and its focus on chord patterns.

Harmony in rock has been described by several commentators as less directional or functional than in conventional tonality, which is due in no small part to the prevalence of pentatonic, modal, and blues-based structures, and the corresponding lack of a leading tone in many styles, deriving from their roots in both the blues and the modal-folk revival. ${ }^{2}$ Related factors include the tendency of large-scale structures to be cyclic rather than goaldirected, and the textural divergence that Allan Moore and more recently David Temperley have called the "melodic-harmonic divorce." In many instances, however, melody and harmony can be analytically reconciled through rhythmic regularization or an expanded conception of "chord tone," encompassing traditional added notes (seconds, fourths, sixths, and sevenths) and extensions (ninths, elevenths, and thirteenths). These nontriadic tones have more complex ratios with the chord root and are thus more acoustically dissonant than triad members. Nonetheless, in many vernacular genres-including blues, jazz, and rock-nontriadic tones are not unstable by definition, in the sense that stylistic constraints require their resolution; common-practice rules of voice-leading and dissonance treatment do not necessarily apply. The relative tension and stability of scale degrees and chord structures in a given song are defined by their immediate harmonic and melodic context against a background of broader stylistic conventions. For example, a dominant-seventh chord in a

2 See Stephenson (2002, 113-14), Carter (2005), and Björnberg (2007, 275). 3 See Moore $(1995,189)$ and Temperley $(2007)$. 
Tin Pan Alley song is likely to resolve, while a dominant-seventh chord in the blues might function as the tonic. The distinction between acoustic dissonance and contextual instability reflects a more general one between dissonance-as-identity and dissonance-as-behavior. ${ }^{4}$ In rock music, both types of dissonance are contextual to some degree, since acoustic dissonance is affected by timbre, and can be increased through the use of distortion until intervals at the consonant end of the continuum, such as thirds, are perceived as dissonant.

Scholarship to date has explored several interpretive paradigms for pitch relationships in rock music: theories of harmonic function, ${ }^{5}$ scale degree, ${ }^{6}$ root motion, ${ }^{7}$ linear motion, ${ }^{8}$ and neo-Riemannian transformations. ${ }^{9}$ Each of these methodologies can provide some understanding of harmonic or melodic behaviors in rock music, but scale-degree theory (which associates characteristic behaviors with chords based on the scale degree of their roots) and harmonic-function theory (which groups chords that behave similarly into larger categories) prove most useful for generalizing about chord patterns. ${ }^{10}$ In many cases, chord hierarchy and function are established or clarified by other musical parameters such as phrase structure, hypermeter, rhythm, texture, consonance, and contour.

In his article on harmonic functionality, Eytan Agmon categorized the diatonic triads on the basis of their common tones and positions relative to the tonic, generating a diatonic-third cycle, shown in Example 1(a). ${ }^{11}$

The functions of tonic, dominant, and subdominant are mapped onto three overlapping semicircles; the prototype for each category is the encircled primary triad. The remaining triads each participate in two function categories: III as tonic or dominant and VI as tonic or subdominant, both of which are

4 For more on this topic see Kopp (1995) and (2002, 5-8).

5 Doll (2007, 1-27). Doll's theory of harmonic function is based on predictive stepwise voice-leading resolutions.

6 Moore (1992) and Everett (2009, 214-301). Moore's modal taxonomy of harmonic patterns requires an elaborate system of categories and the assignment of a single governing mode to each pattern.

7 See Stephenson $(2002,102-05)$ and Carter (2005). Theories of root motion are typically predicated on a binary opposition of progression versus retrogression (descending fifths and thirds and ascending seconds versus ascending fifths and thirds and descending seconds) that reflects no chord hierarchy, despite the clear tonics established in many, if not most, songs.

8 Schenkerian techniques have been adapted in essays by Walter Everett, Lori Burns, and other authors, in Covach and Boone (1997), Everett (2008), and other works. Schenkerian paradigms of linear motion are potentially powerful explicators of melody, but presume a concern for voiceleading and counterpoint often absent from the harmony layer, especially when it is iterated by rhythm guitar rather than keyboard (see Moore [2001, 59-60], for a discussion of the differences between keyboard-based and guitar-based compositional harmony and voice-leading).

9 Capuzzo (2004). Neo-Riemannian transformations are most successfully applied to post-1990 alternative genres, which favor chromatic thirds and other cross-relations.

Io Tymoczko (2003) explores and compares the explanatory power of three of these paradigms, root-motion, scale-degree, and harmonic-function theories, as applied to harmonic motion in Bach chorales.

II Agmon (1995, 199-202).

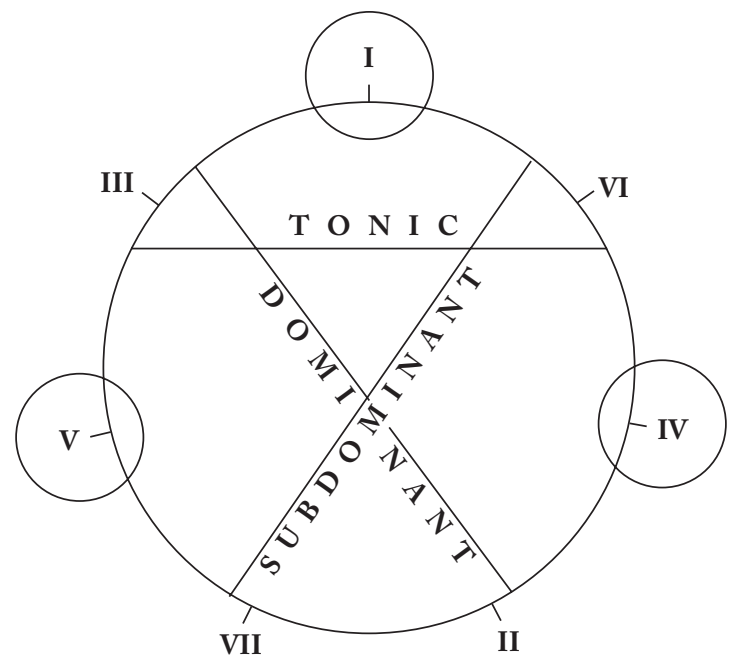

EXAMPLE I(A). Harmonic functions of tonal triads (Agmon [1995, 201])

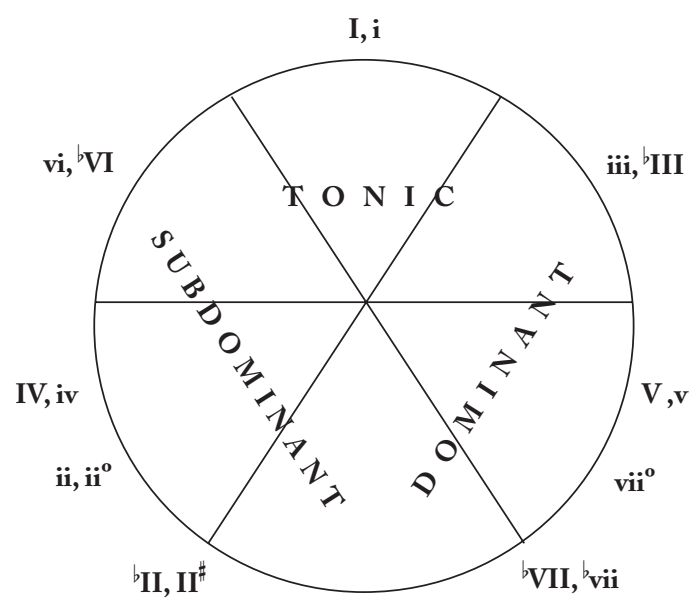

EXAMPLE I(в). Harmonic functions of modal triads

familiar ideas from Riemann's Vereinfachte Harmonielebre, and VII and II as dominant or subdominant, which have precedents in Daniel Harrison's theory of harmonic function, as each contains both dominant- and subdominant-functioning scale degrees. ${ }^{12}$ In practice, non-primary triads might express either of their two potential functions, or aspects of both. Agmon's examples of dominant-functioning supertonics are not convincing-most analysts would probably label them neighbor chords-and no example of a subdominant-functioning leadingtone triad is given. However, if the subtonic triad is incorporated into the model, as in Example 1(b), its dual potential function in rock music as dominant or subdominant, discussed further below, is neatly explained, as are the roles of bI as both a subdominant-functioning Neapolitan and a dominant-functioning tritone substitute, and the similar dual roles of Lydian $\mathrm{II}^{\sharp}$.

I2 See Harrison (1994, Chapter 2, especially 50-55 and 60-66). 
Artist, Title (Year), Formal Section

The Doors, "The End" (1967), A section

Steppenwolf, "Born to be Wild" (1968), chorus

J.J. Cale, "Cocaine" (1976), verse

Grateful Dead, "Fire on the Mountain" (1978)

The Doors, "Break on Through" (1967)

Black Sabbath, "Paranoid" (1970), verse

Deep Purple, "Child in Time" (1970)

R.E.M., "The One I Love" (1987), A section

Santana, "Evil Ways" (1969)

The Doors, "Riders on the Storm" (1971), main riff

Styx, "Renegade" (1978), verse

Pink Floyd, "Another Brick in the Wall" (1979), verse

Grateful Dead, "Brokedown Palace” (1970), refrain
Mode

Mixolydian
Mixolydian
Mixolydian
Mixolydian

Aeolian

Aeolian

Aeolian

Aeolian

Dorian

Dorian

Dorian

Dorian

(Lydian) $\underline{\text { Progression }}$

I- ${ }^{b}$ VII

I- $-{ }^{b}$ VII

I- - VII

I- ${ }^{b}$ VII

i- $-^{b}$ VII

i- ${ }^{b}$ VII-i

${ }^{b} \mathrm{VII}-\left.\mathrm{i}\right|^{b} \mathrm{VI}-{ }^{b} \mathrm{VII}$

$i^{7}-{ }^{b} V_{I I}{ }^{\text {sus2 }}-i^{7}$

i-IV

i-IV-i ${ }^{7}-I V$

$\mathrm{i}^{7}-\mathrm{IV}_{4}^{6}$

i-IV

I-III ${ }^{\#}-\mathrm{IV}-\mathrm{I}-\mathrm{II}{ }^{\#}$
Function

T-D

T-D

T-D

T-D

T-D

T-D-T

D-T $\mid$ S-D

T-D-T

T-S

T-S-T-S

T-S

T-S

EXAMPLE 2. Modal progressions with conventional tonal functions

In Example 1(b), I have expanded the model to include these diatonic modal triads, adjusted the notation to reflect triad qualities, and reversed the positions of the dominant and subdominant areas to align with the traditional flat and sharp sides of the circle of fifths. Tonics contain scale-degree $\hat{1}$ and/or some form of $\hat{3}$, subdominants contain forms of $\hat{4}$ and/or $\hat{6}$, the adjacencies above and below the dominant degree $\hat{5}$, and dominants contain forms of $\hat{7}$ and/or $\hat{2}$, the adjacencies above and below the tonic degree $1 .{ }^{13}$ Doll has observed that in pentatonic systems, in which the two sizes of scale step are major second and minor third, the adjacencies above and below the tonic that suggest dominant function could also be $b \hat{3}$ or $\hat{6} ;{ }^{14}$ similarly, the adjacencies surrounding the dominant are $\hat{3}$ and $b \hat{\imath}$. Pentatonic structures are explored in greater detail in a later section of this article.

In distinction to the focus of this study, a large percentage of pop-rock music is conventionally tona $1^{15}$ - particularly that of the 1950s and early 1960s, and particularly in genres better described as pop than rock, which are more likely to follow classical models of voice leading. Since the diatonic major system can serve as both a statistical and historical norm, Roman numerals in my examples are shown in relation to major. A valid criticism of this notation is that it symbolizes the flat-side triads $b \mathrm{III}, b \mathrm{VI}$, and bVII as nondiatonic, although in the repertory under consideration these chords are at least as normative as their diatonic counterparts—in the case of bVII, significantly more so. Indeed, the use of flat-side triads has been a harmonic code for rock since the late 1960s. Nonetheless, I have adopted this notation

I3 Ibid.

I4 Doll (2007, 23-24).

I5 On this see Everett $(2004, \S 3)$. because it seems the clearest of available systems, requires the least explication, and is in the widest current use. Triad qualities are signified by upper- and lower-case for major and minor, ${ }^{\circ}$ and ${ }^{+}$for diminished and augmented, and superscript 5 for power chords. ${ }^{16}$ Jazz-chart symbols are used for chord extensions and alterations.

As suggested by the diagram in Example 1(b), many modal progressions can be explained in conventionally tonal terms, especially those in the Mixolydian, Dorian, and Aeolian modes, which have a long tradition of folk-music harmonizations and are the modes closest to major and minor. Example 2 presents a selection of simple characteristic progressions in each mode (many consisting of the tonic and one other chord), and their tonal functions. ${ }^{17}$ In the first two categories of Example 2, the subtonic most typically functions as a dominant. The replacement of the leading tone with the subtonic, and the neighboring position of the chord root, creates a flattened affect, expressing primarily dominant function but also embodying subdominant aspects, as reflected in Example 1(b). The Dorian major IV often serves its common tonal function of a plagal upper neighbor to

I6 Power chords are normative vertical structures in hard rock and heavy metal: open fifths or, less commonly, fourths, often with octave doubling. These chords are a consequence of the heavy use of distortion, an overloading of the signal through an amplifier, which increases the overall complexity of the sound wave and in particular the audibility of the upper partials. Distortion renders chord thirds dissonant because the overtones intermodulate to create sum and difference tones unrelated to the original fundamental; also, a major third is often audibly present as the fifth overtone, but at a frequency dissonant with a sounded major third.

I7 These examples are discussed in greater detail in Biamonte, "Modal Function in Rock and Metal" (forthcoming). 
the tonic. Other instances of the chord progressions shown in this example can be readily found in rock music.

By contrast, the Lydian mode is rare in rock practice-as it has always been in art music-and is usually expressed as an inflection of the supertonic, rather than as a diatonic modality. In the Grateful Dead's gospel-tinged "Brokedown Palace," the progression in the first half of the refrain ends on a major II chord, which occupies the normal position of a dominant. I hear it as a substitute dominant that offers the "wrong" leading tone, to scale-degree $\hat{5}$ instead of to $\hat{1}$. There is no V chord in the body of the song; all the cadences are plagal. The Phrygian and Locrian modes are also rare in rock practice, although they are quite common in heavy metal. ${ }^{18}$

\section{DOUBLE-PLAGAL PROGRESSIONS}

Having surveyed some simple two-chord modal progressions, I shall move on to more complex patterns of three chords, before examining larger tonal structures. This section of the article surveys in theory and practice a pair of brief harmonic progressions that serve as stylistic markers of classic rock and behave in very similar ways: the double-plagal progression, (I)bVII-IV-I, and the Aeolian cadence or progression, (I)-bVIbVII-I. ${ }^{19}$ Both patterns can be analyzed as modal or modally inflected harmonic progressions, repeated root motions, or chordal realizations of essentially linear structures. These interpretations are considered in greater detail below.

A basic version of the double-plagal progression, bVII-IV-I, is shown in Example 3(a). It can be interpreted as diatonic to the Mixolydian mode, as an instance of major-minor mixture, or more simply as a chromatic inflection of major. ${ }^{20}$ The progression is often expressed as two descending-fourth root motions, which can be construed as a retrogressive inversion of the conventional tonal descending-fifth progression II-V-I, shown in Example 3(b). Although redolent of the mythical "undertone series," the symmetry of this construct is nonetheless appealing. The successive descending-semitone resolutions $\mathrm{B} b-\mathrm{A}$ and $\mathrm{F}-\mathrm{E}$ in Example 3(a) are mirrored by the successive leading-tone resolutions $F \#-G$ and $B-C$ in Example 3(b). It is possible to hear the subtonic as functioning differently on multiple structural levels: in its immediate context as IV/IV but as a dominant

I8 See Biamonte (forthcoming).

I9 Gary Burns includes the first of these chord patterns among his seven "harmony hooks," which he identifies as genre conventions of popular music; although he does not discuss more specific genres, all of his examples can be categorized as classic rock $(1987,10)$. Everett describes the double-plagal cadence as "a staple of rock repertoires" and the Aeolian cadence as a common inflection of major-mode songs (2008, 154 and 157-58).

20 Everett asserts that "there is nothing necessarily modal about the progression ... (one might similarly say that the raised fourth scale degree usually calls forth Lydian qualities, which it almost never does)" (2008, 155). However, the lowered seventh degree is more strongly characteristic of the modal system than the raised fourth, as $b \hat{7}$ is diatonic to five out of the seven modes but $\sharp \hat{4}$ is diatonic only to Lydian. More generally, the commonly used modes in rock and folk are those on the flat side of major (Ionian), between major and minor: Mixolydian, Dorian, and Aeolian.

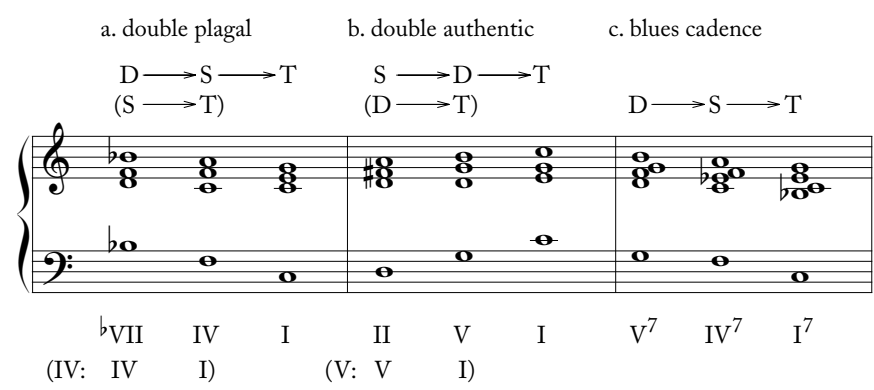

EXAMPLE $3(\mathrm{~A}-\mathrm{C})$. Double-plagal progression and isomorphic tonal
and blues progressions

in relation to the tonic, just as $\mathrm{V} / \mathrm{V}$ serves as the dominant of $\mathrm{V}$ but as a chromaticized subdominant in relation to the tonic. In a different path to a similar view of the double-plagal function, the subtonic, which includes forms of the dominant degrees $\hat{2}$ and $\hat{7}$, replaces $V^{7}$ in the classic blues cadence $V^{7}-I^{7}-I^{7}$, shown in Example 3(c), with idiomatic parallel perfect fifths and octaves. The Beatles' "Taxman" (1966) is an example of a blues with a bVII-IV-I cadence. ${ }^{21}$

In a contrasting view, the double-plagal progression is a linear motion deriving from neighboring $6 / 4$ chords that are given consonant root support. Everett considers IV to be a contrapuntal neighbor to I, on the grounds that the $\hat{6}-\hat{5}$ and $\hat{4}-\hat{3}$ motions are stronger determinants of function than $\hat{4}-\hat{1}{ }^{22}$ In the "neighboring" and "passing" categories of Example 4 the linear motion is perceptually stronger than the harmonic motion.

The double-plagal pattern has one final possible interpretation; that of conforming to diatonic major in a different key: the chords of Example 3(a) could be analyzed as IV-I-V in F major rather than bVII-IV-I in C major or Mixolydian. In a given musical context, additional pitch cues often contribute to the establishment of a clear tonic. For example, the G-D-A progression in the chorus of Neil Young's "Down By the River" (1969) is contextualized by the $\mathrm{Em}^{7}-\mathrm{A}$ oscillations of the verse and the chorus tag, which function as $\mathrm{ii}^{7}-\mathrm{V}$, pointing to $\mathrm{D}$ as tonic and the chorus pattern as IV-I-V rather than bVII-IV-I. The same progression in the chorus of Creedence Clearwater Revival's "Up Around the Bend" (1970) is similarly cast in D by the clear I-I-V-I pattern of the verses (D-D-A-D). In songs lacking other formal sections in the same key, additional musical parameters can often help to identify a tonal center. Despite the mid-phrase tonics on weak beats in the preceding two examples, tonic chords are more likely to occur at points of structural demarcation such as the beginnings or ends of phrases, and are often metrically or rhythmically emphasized as well. ${ }^{23}$ Texture, contour, and consonance may provide further cues. In Warren Zevon's "Werewolves of London” (1978), the melodic

2I Doll offers the example of "The Shadow Knows" by Link Wray and His Ray Men (1964); see Doll (2009, 24, Note 42).

22 See Everett $(2008,154-55)$.

23 This point is also made by Capuzzo $(2009,160)$. A more extensive list of criteria is given in Doll $(2007,64)$. 


\begin{tabular}{|c|c|c|}
\hline Function & $\underline{\text { Progression }}$ & Examples \\
\hline Neighboring & $\begin{array}{l}\mathrm{I}-(\mathrm{IV})-\mathrm{I} \mid \mathrm{IV}-\left({ }^{b} \mathrm{VII}\right)-\mathrm{IV} \\
\mathrm{I}-\mathrm{IV}-\left({ }^{b} \mathrm{VII}\right)-\mathrm{IV} \\
\mathrm{I}-\mathrm{IV}-\left({ }^{b} \mathrm{VII}{ }^{\text {add } 9}\right)-\mathrm{IV} \\
\mathrm{I}-\mathrm{IV}^{\text {add } 9}-\left({ }^{b} \mathrm{VII}{ }^{6 / 9}\right)-\mathrm{IV}^{\text {add } 9} \\
\mathrm{I}-{ }^{b} \mathrm{VII}-(\mathrm{IV})-{ }^{b} \mathrm{VII}\end{array}$ & $\begin{array}{l}\text { Buddy Holly and the Crickets, "Not Fade Away" (1957) } \\
\text { The Romantics, "What I Like About You" (1980) } \\
\text { Talking Heads, "And She Was" (1985), chorus } \\
\text { John Cougar Mellencamp, "R.O.C.K. in the U.S.A." (1985) } \\
\text { Led Zeppelin, "Communication Breakdown" (1969), verse }\end{array}$ \\
\hline Passing & $\begin{array}{l}\mathrm{I}-\left({ }^{b} \mathrm{VII}\right)-\mathrm{IV}-\left({ }^{b} \mathrm{VII}\right) \\
\mathrm{I}-\left({ }^{b} \mathrm{VII}\right)-\mathrm{IV}-\left({ }^{b} \mathrm{VII}\right)\end{array}$ & $\begin{array}{l}\text { Bob Seeger, "Night Moves" (1976), verse } \\
\text { Simple Minds, "Don't You Forget About Me" (1985), verse and chorus }\end{array}$ \\
\hline Circular & $\begin{array}{l}\mathrm{I}-{ }^{b} \mathrm{VII}-\mathrm{IV}-\mathrm{I} \\
\mathrm{I}-{ }^{b} \mathrm{VII}-\mathrm{IV}-\mathrm{I} \\
\mathrm{I}-{ }^{b} \mathrm{VII}-\mathrm{IV}-\mathrm{I} \\
\mathrm{I}-{ }^{b} \mathrm{VII}-\mathrm{IV}-\mathrm{I}\end{array}$ & $\begin{array}{l}\text { Beatles, "Hey Jude" (1968), coda } \\
\text { Rolling Stones, "Sympathy for the Devil" (1968), verse } \\
\text { Steve Miller, "Rock'n’Me" (1976), verse and chorus } \\
\text { Guns'n'Roses, "Sweet Child o' Mine" (1987), verse }\end{array}$ \\
\hline Closed & $\begin{array}{l}\mathrm{I}^{7}-\mathrm{I}^{7 \# 9}:\left.\right|^{b} \mathrm{VII}^{7}-\mathrm{IV}^{7 \# 9}-\mathrm{I}^{7} \\
{ }^{b} \mathrm{VII}-\mathrm{IV}-\mathrm{I}\end{array}$ & $\begin{array}{l}\text { Beatles, "Taxman" (1966), refrain } \\
\text { Beatles, "With a Little Help from My Friends" (1967), chorus }\end{array}$ \\
\hline Open & $\begin{array}{l}1^{5}-{ }^{b} 7^{5}-4^{5} \\
1^{5}-{ }^{b} 7^{5}-4^{5} \\
\text { I-IV-b VII : }\left.\right|^{b} \text { VI- }{ }^{b} \text { VII-I }\end{array}$ & $\begin{array}{l}\text { AC/DC, "Back in Black" (1980), verse } \\
\text { ZZ Top, "Sharp Dressed Man" (1983), beginning of verse } \\
\text { The Kinks, "Lola" (1970), verse }\end{array}$ \\
\hline
\end{tabular}

emphasis on $\mathrm{G}$ and repeating $\mathrm{B}-\mathrm{A}-\mathrm{G}$ melodic descent in the piano riff establish $\mathrm{G}$ as tonic, and thus the chord pattern $\mathrm{D}-\mathrm{C}-\mathrm{G}$ functions as $\mathrm{V}-\mathrm{IV}-\mathrm{I}$. In contrast, the same pattern in Lynyrd Skynyrd's "Sweet Home Alabama” (1974) is more readily heard as bVII-IV-I in D because of the melodic F\#-E-D descent, although the guitar solo emphasizes G. ${ }^{24}$

In light of these various theoretical interpretations of the double-plagal progression, I shall consider its behavior as realized in rock practice. A distinction can be made between several versions of the pattern that express different phrase functions, as shown in Example 4. ${ }^{25}$ These categories are based primarily on phrase structure in combination with metric and hypermetric accentuation, and secondarily on emphasis through duration, texture, contour, and consonance.

In the first two groups, neighboring and passing progressions, linear relationships take precedence over the immediate chordal successions; harmonies with lesser structural weight are

24 "Sweet Home Alabama" is a famously ambiguous example, the key of which the band members themselves interpret differently; see Guitar Edge, July/ August (2006), and Maximum Guitar 8 (1998, 24). Both "Werewolves of London" and "Sweet Home Alabama" are discussed and compared in Stephenson (2002, 45-46) and Doll (2007, 69-77). In Kid Rock's "All Summer Long" (2008), both songs are sampled against a background of $G$ major.

25 For additional examples of double-plagal progressions see Burns (1987, 10), Moore (1992, 98), Carter (2005, 122-23 and 136-41), and Everett (2008, 154-56). shown in parentheses. In the remaining categories, bVII and IV occur on the same structural level and are differentiated by the position of the tonic; circular progressions are bounded by the tonic and serve to prolong it, closed progressions arrive on the tonic as a goal, and open progressions depart from an initial tonic. ${ }^{26}$ All of the chord progressions shown here are immediately repeated, in most cases numerous times, constituting harmonic musemes that generate a structural framework. ${ }^{27}$ In this table and those following, the chord progression comprises the basic harmonic material of the specified section or the entire song (introductions, solos, and codas excluded). Within each category, songs are listed in chronological order except for anomalous examples of harmonic patterns, which have been placed at the ends of their categories.

The first category in Example 4 epitomizes Everett's reading of the double-plagal progression, in which $\mathrm{I}$ is prolonged by an upper-neighbor IV, which is in turn elaborated by an upperneighbor bVII. The tonics in these examples are stated on hypermetric downbeats and serve as stable initiating points of arched melodic contours. The most obvious instance is found in "Not

26 Missing from this set of categories is a provision for phrases that neither begin nor end on the tonic, which are comparatively rare in this repertory and typically occur in transitional sections such as prechoruses and bridges.

27 Middleton defines musematic repetition as extended and essentially invariant repetition of a museme, the smallest meaningful musical unit in a system (1990, 17ff. and 189ff.). 


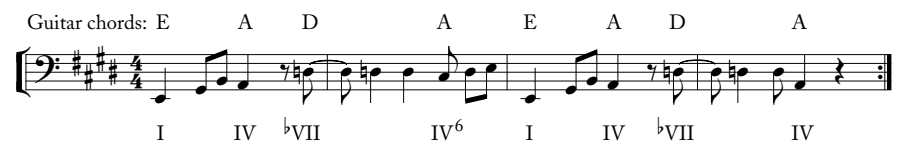

EXAMPLE 5. Neighboring double plagal: $I-I V-$ (bVII)-IV; The Romantics, "What I Like About You," bass line (regularization)

Fade Away" by Buddy Holly and the Crickets, in which the guitar and backing vocals state complete neighbor figures in parallel thirds. The next three songs in this category feature nested upper neighbors in the form of melodic $\hat{5}-\hat{6}-\vec{b}-\hat{b}$ progressions in the guitar or vocals, in which $\hat{b}$ is a neighbor to $\hat{5}$ and $b \hat{7}$ is a more foreground-level neighbor to $\hat{b}^{28}$

In the verse of The Romantics' "What I Like About You," the tonic $\mathrm{E}$ is emphasized melodically and is registrally accentuated as the lowest note of the bass part (shown in Example 5). The unstable harmonic status of bVII as an auxiliary chord is mirrored by its rhythmic expression on the off-beats; compare the more stable effect of the clearly arpeggiated tonic on alternate downbeats, coinciding with the accented sustained notes in the vocals. The chord pattern in the guitar segments parses the song into 2-bar groupings, but the bass pattern and rhyme scheme of the lyrics group these into 4-bar units. The bass part creates a subtle antecedent-consequent effect by answering the first-inversion subdominant at the end of the second measure with a root-position subdominant at the end of the fourth measure, which adds interest to the repeated chord pattern.

Several examples in this category have structural dominants occurring later in the song that confirm the initial harmony as tonic: these occur in "What I Like About You" at the end of the solo break, and in "R.O.C.K. in the U.S.A." and "Communication Breakdown" at the end of each chorus. As indicated by the added notes in their chord patterns, "And She Was" has a tonic pedal throughout, and "R.O.C.K. in the U.S.A." has pedals on $\hat{1}$ and $\hat{5}$. These pedal points on degrees of the tonic triad serve to clarify the subordinate status of the non-tonic harmonies.

In the verse riff of Led Zeppelin's "Communication Breakdown" (Example 6), the positions and roles of the harmonies are reversed: IV functions as a neighbor chord to the surrounding bVII harmony, which in turn functions as a larger-scale neighbor to I. Although IV is in a metrically stronger position, bVII is accented by its longer duration, crash-cymbal accompaniment, and its registral shift, which creates a dissonant leap of a compound seventh and a high point in the contour. The implied nested lower-neighbor structure of $\hat{8}-\rightarrow \hat{7}-b \hat{6}-b \hat{7}$ is not explicit because of the tonic degree's registral disjunction, which is perhaps emblematic of the song's subject. Robert Plant's vocal line is a series of blues-scale descents from the dominant degree, creating a larger-scale disjunction against the harmony that reflects the band's strong blues and folk influences.

28 Doll has dubbed this the "rogue riff," and observed that it typically functions either as nested neighbors in a double-plagal structure (as it does here), or as a composing-out of a dominant-seventh harmony, in which $\hat{5}$ and $b \hat{\gamma}$ are connected by passing $\hat{6}$. See Doll $(2007,174 \mathrm{ff}$.$) .$

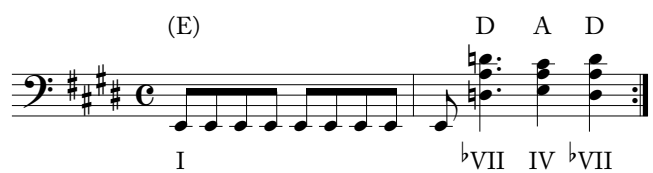

EXAMPle 6. Neighboring double plagal: I-bVII-(IV)-bVII; Led Zeppelin, "Communication Breakdown," verse riff

The passing progressions in Example 4 employ the same chords, in the same order, as those in "Communication Breakdown," but the hierarchy is different: the motion is an inverted arch from I through bVII to IV and back, in conjunct motion except for the bass. In the verse of Bob Seger's "Night Moves" (Example 7), bVII is metrically weaker and durationally shorter than I and IV, which are on hypermetric downbeats and three times as long. The bass (not shown) enters after the first verse, playing the roots of I and IV but not of $b \mathrm{VII}$, instead inserting decorative fills underneath the guitar harmony.

The circular double-plagal progression prolongs the tonic, as in the verse of the Rolling Stones' "Sympathy for the Devil" (Example 8 shows the piano part). Although IV is hypermetrically stronger and is melodically and rhythmically emphasized by the arpeggiation in the piano bass, bVII and IV share duration and texture, and the bass guitar plays the same rhythmic pattern on the chord root in each measure. The verse progression prepares the structural dominant at the beginning of the chorus (as it does in "Sweet Child o' Mine"), confirming the tonic asserted by the leading tone in the third measure of the piano bass. A dominant pedal is added in the backing vocals in the third verse- part of a gradual increase in texture, a common compositional strategy in rock songs. As in "And She Was" and "R.O.C.K. in the U.S.A.," the pedal points are dissonant against the nontonic chords, reinforcing their subsidiary status; a similar effect is created by the vocal appoggiaturas in the coda of "Hey Jude," the lead and backup vocals in the chorus of "Rock'n Me," the guitar riff in the introduction of "Sweet Child o' Mine," and the

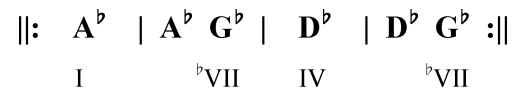

EXAMPle 7. Passing double plagal: I-(bVII)-IV-(bVII); Bob Seger, "Night Moves," verse chord pattern

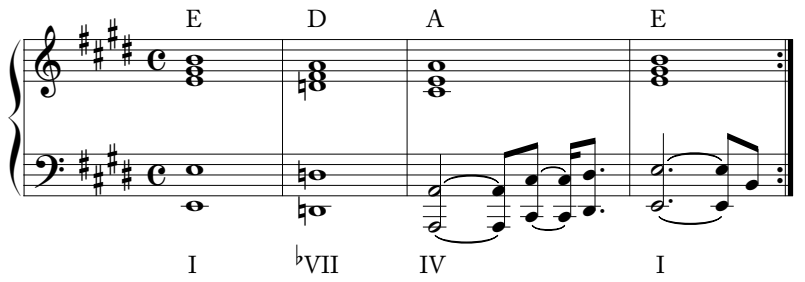

EXAmple 8. Circular double plagal: I-bVII-IV-I; Rolling Stones, "Sympathy for the Devil," verse (piano part) 


\section{$\left\|: \mathbf{D}^{7}\left|\mathbf{D}^{7}\right| \mathbf{D}^{7 \text { \#9 }}\left|\mathbf{D}^{7 \sharp 9}: \| \mathbf{C}^{7}\right| \mathbf{G}^{7 \sharp 9}\left|\mathbf{D}^{7}\right| \mathbf{D}^{7} \mid\right.$ $\begin{array}{llllllll}\mathrm{I}^{7} & \mathrm{I}^{7} & \mathrm{I}^{7 \pm 9} & \mathrm{I}^{7 \neq 9} & { }^{b} \mathrm{VII}^{7} & \mathrm{IV}^{7 \pm 9} & \mathrm{I}^{7} & \mathrm{I}^{7}\end{array}$}

EXAMPle 9. Closed double plagal:bVII-IV-I; Beatles, "Taxman," verse chord pattern (modified 12-bar blues)

synthesizer part in "Don't You Forget About Me" in the previous category, passing double-plagal progressions. Like the passing progressions, all of the circular double-plagal patterns have a largely conjunct contour of an inverted arch.

Since the closed double-plagal progression begins off-tonic, it typically occurs once the tonic has been established, in refrains or choruses, where it serves a cadential function. In the verses of the Beatles' "Taxman" (see Example 9), the doubleplagal pattern occurs as the third phrase of a 12-bar blues structure, following two phrases of tonic harmony. The use of $b \mathrm{VII}^{7}$ rather than $V^{7}$ in $m .9$ results in a background scale with flexible third and sixth, rather than the more usual flexible third and seventh. The lowered sixth $(\mathrm{B} b)$ is retained as a blue third $(\$ 9)$ in the following chord, IV ${ }^{7 \sharp 9}$. In the chorus of "With a Little Help from My Friends," the repeated bVII-IV-I progression serves as a plagal extension of the authentic cadence that concludes the verse, while the vocal part provides a tonic pedal that structurally, although not stylistically, resembles an "Amen" cadence.

By contrast, the open double-plagal progression is typically found at formal beginnings, such as the verse of AC/DC's "Back in Black" (Example 10). The tonal context of this version of the progression is potentially ambiguous, as it is equivalent to V-IV-I in the key a fourth below. Ambiguity in this instance is fostered by the harmonic rhythm: the last chord of the riff is twice as long as the others, and the greater weight of this durational accent suggests tonic function. In most cases, however, other formal sections or musical parameters establish a governing tonic. In "Back in Black," the tonic function of $\mathrm{E}$ becomes clear with the arrival of the dominant at the beginning of the chorus (not shown).

In like manner, the tonic of ZZ Top's "Sharp Dressed Man" is confirmed by the dominant at the beginning of the refrain, which is the third phrase of a 12-bar blues. The first two phrases are open double-plagal progressions that prepare the dominant, with the vocal part providing a tonic pedal, as in several of the preceding examples. Other examples of $\mathrm{I} \rightarrow \mathrm{V} \mathrm{VII}-\mathrm{IV}$ progressions are not difficult to find: Rolling Stones, "The Last Time" (1965), verse; Jerry Garcia, "Deal" (1972), chorus; Boston, "More Than a Feeling" (1976), verse; and many others. More unusual is the I-IV $\rightarrow$ VII progression in The Kinks' "Lola," which reverses the

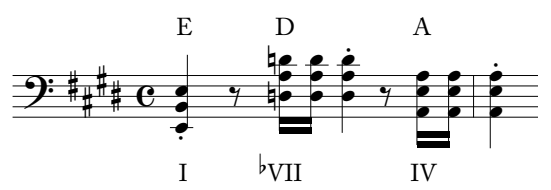

EXample io. Open double plagal: $I-b V I I-I V ; A C / D C$, "Back in Black," verse riff

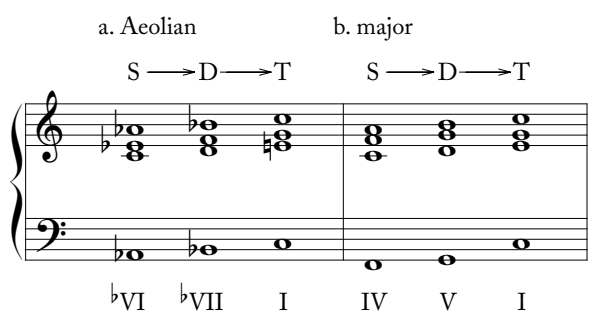

EXAMPle ir. Aeolian progression and isomorphic tonal progression

normal order of the plagal harmonies in a closed double-plagal progression. (It is tempting but perhaps not credible to relate this harmonic reversal to the gender-bending depicted in the lyrics.) Musically, the subtonic in the fourth measure of the pattern provides a smooth transition to the Aeolian cadence at the end of the verse.

\section{AEOLIAN PROGRESSIONS}

A basic version of the Aeolian progression, bVI-bVII-I or bVI-bVII-i, is shown in Example 11(a), with idiomatic parallel fifths and octaves. This pattern, which originated as a cadential formula, is also used in other configurations. The version with minor tonic is diatonic to Aeolian, while the version with major tonic is modally mixed, featuring a cross-relation between $b \hat{3}$ and $₫ \hat{3}$. Aeolian progressions comprise two successive root movements upwards by whole step, and can be interpreted as either a substitution by third for the tonal cadence IV-V-I, shown in Example 11(b), or an expansion of the modal subtonic cadence bVII-I. Both readings imply the harmonic functions S-D-T, a satisfactory interpretation because bVI contains the subdominant degree $b \hat{b}$ (although it does not progress to $\hat{5}$ ), and bVII contains forms of the dominant degrees $\hat{2}$ and $\hat{7}$. Aeolian progressions can also be understood more simply as linear motions to or from the tonic, with perfect-fifth or triad doublings that express no additional harmonic functionality. Such parallelchord patterns are highly idiomatic to the guitar, because of the ease of sliding barre chords up and down the fretboard.

The tonics of Aeolian progressions are less ambiguous than those of double-plagal progressions. A series of major triads ascending by whole step in rock music is much more likely to have the tonic as a goal than as an initiating point, and thus to represent bVI-bVII-I rather than I-II-III (or, less commonly, bIII-IV-V, arriving on the dominant as a goal). Ascending stepwise chord progressions above the tonic are usually diatonic to major and have IV or $V$ as a goal; examples include the I-ii - iii $-I V$ verse of the Beatles' "Here, There, and Everywhere" (1966) and the I-ii-iiiIV-V verse of Bob Dylan's "Like a Rolling Stone" (1965). An atypically chromatic example is the verse of Jim Croce's "Bad, Bad, Leroy Brown" (1973), in which the seventh chords on $\hat{2}$ and $\hat{3}$ are

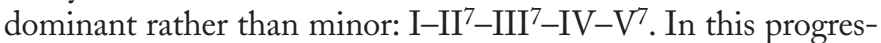
sion, $\mathrm{II}^{7}$ functions as $\mathrm{V}^{7} / \mathrm{V}$, and $\mathrm{III}^{7}$ as a deceptive resolution in which vi/V is transformed into a dominant seventh. Similarly, $\mathrm{III}^{7}$ functions as $\mathrm{V}^{7} / \mathrm{vi}$, resolved deceptively by $\mathrm{VI} / \mathrm{vi}$. The chord pattern in the first section of The Who's "See Me, Feel Me" (1969), 
MUSIC THEORY SPECTRUM 32 (2OIO)

\begin{tabular}{|c|c|c|}
\hline$\underline{\text { Function }}$ & $\underline{\text { Progression }}$ & Examples \\
\hline Neighboring & $\begin{array}{l}\mathrm{i}-\left({ }^{b} \mathrm{VII}\right)-{ }^{b} \mathrm{VI}-\left({ }^{b} \mathrm{VII}\right) \\
\mathrm{i}-{ }^{b} \mathrm{VII}-\left({ }^{b} \mathrm{VI} \mathrm{I}^{6 / 9}\right)-{ }^{b} \mathrm{VII}\end{array}$ & $\begin{array}{l}\text { Aerosmith, "Dream On" (1973), chorus } \\
\text { Blue Öyster Cult, "Don’t Fear the Reaper" (1976), beginning of verse; }\end{array}$ \\
\hline Passing & $\begin{array}{l}\mathrm{i}-\left({ }^{b} \mathrm{VII}\right)-{ }^{b} \mathrm{VI}-\left({ }^{b} \mathrm{VII}\right) \\
\mathrm{I}-\left({ }^{b} \mathrm{VII}\right)-{ }^{b} \mathrm{VI}-\left({ }^{b} \mathrm{VII}\right) \\
\mathrm{i}-\left({ }^{b} \mathrm{VII}\right)--^{b} \mathrm{VI}-\left({ }^{b} \mathrm{VII}\right) \\
\mathrm{i}-\left({ }^{b} \mathrm{VII}{ }^{\text {add }}\right)-{ }^{b} \mathrm{VI}^{\Delta 7}-\left({ }^{b} \mathrm{VII}\right. \\
\left.\mathrm{Iddd}^{\mathrm{add}}\right)\end{array}$ & $\begin{array}{l}\text { Bob Dylan, "All Along the Watchtower" (1967) } \\
\text { Rolling Stones, "Gimme Shelter" (1969), chorus } \\
\text { Led Zeppelin, "Stairway to Heaven" (1971), final section } \\
\text { Kansas, "Carry On Wayward Son" (1976), beginning of verse }\end{array}$ \\
\hline Circular & $\begin{array}{l}1^{5}-{ }^{b} 6^{5}-{ }^{b} 7^{5}-1^{5} \\
\mathrm{i}-{ }^{b} \mathrm{VI}--^{b} \mathrm{VII}-\mathrm{i} \\
\mathrm{I}-{ }^{b} \mathrm{VII}--^{b} \mathrm{VI}-{ }^{b} \mathrm{VII}-\mathrm{I}\end{array}$ & $\begin{array}{l}\text { Derek and the Dominos, "Layla" (1970), chorus } \\
\text { Patti Smith, "Because the Night" (1978), chorus } \\
\text { Grand Funk Railroad, "We're an American Band" (1973), intro and ch }\end{array}$ \\
\hline Closed & $\begin{array}{l}{ }^{b} \mathrm{VI}^{(7 \sharp 9)}-{ }^{b} \mathrm{VII}{ }^{(7)}-\mathrm{I} \\
(\mathrm{i}){ }^{b} \mathrm{VI}-{ }^{b} \mathrm{VII}-\mathrm{i}\end{array}$ & $\begin{array}{l}\text { Jimi Hendrix, "Voodoo Child (Slight Return)" (1968), refrain } \\
\text { Bon Jovi, "Livin' on a Prayer" (1986), verse and pre-chorus }\end{array}$ \\
\hline Open & $\begin{array}{l}1^{5}-{ }^{b} \mathrm{VI}--^{b} \mathrm{VII} \\
\mathrm{i}--^{b} \mathrm{VI}--^{b} \mathrm{VII} \\
1^{5}-{ }^{b} 6^{5}--^{b} 7^{5}\end{array}$ & $\begin{array}{l}\text { Alice Cooper, "I'm Eighteen" (1970), verse and beginning of chorus } \\
\text { Heart, "Crazy on You" (1976), beginning of chorus } \\
\text { Scorpions, "No One Like You" (1982), chorus }\end{array}$ \\
\hline
\end{tabular}

EXAMPLE I2. Aeolian progression types

$\mathrm{E}^{\Delta 7}-\mathrm{F}^{\text {sus } 2}-\mathrm{G}$, is initially tonally ambiguous, but the melodic focus on $\mathrm{G}$ and pentatonic descent to $\mathrm{D}$, and the added-note dissonances on the first two chords, suggest $b \mathrm{VI}^{\text {maj7 }}-b \mathrm{VII}{ }^{\text {sus } 2}-\mathrm{I}$ as the most plausible analysis. The key of $\mathrm{G}$ is confirmed by the dominant pedal in the bass at the end of the section.

Like double-plagal progressions, Aeolian progressions can be categorized on the basis of their formal functions, as shown in Example $12 .{ }^{29}$ In neighboring and passing Aeolian progressions, the tonic is prolonged through linear motion, while in circular progressions it is prolonged through harmonic motion. ${ }^{30}$ These three pattern-types usually have inverted-arch contours in parallel motion with the bass. Closed Aeolian progressions ascend in parallel to cadence on the tonic, while open progressions descend from it and then return in a downward arch.

Because the chord structure of the Aeolian progression spans a stepwise third, it lends itself much more readily to passing patterns than to neighboring ones, and both of the examples in the neighboring category require disclaimers. Example 13 shows the guitar figuration that begins the verse of Blue Öyster Cult's "Don't Fear the Reaper." In this excerpt, $b \mathrm{VI}$ is subsidiary to bVII because it is stated against the pedal tones G and D, which are consonant with the surrounding subtonic harmony, implying a nested lower-neighbor pattern. The structure of the

29 For more examples of Aeolian progressions see Burns $(1987,10)$, Moore (1992, 87), Carter (2005, 99-100), Everett (2008, 157-58), and Everett $(2009,260)$.

30 Björnberg (1984) and Tagg (2002) refer to the passing Aeolian progression, as well as an unadorned oscillation between the tonic and submediant, as an "Aeolian pendulum."

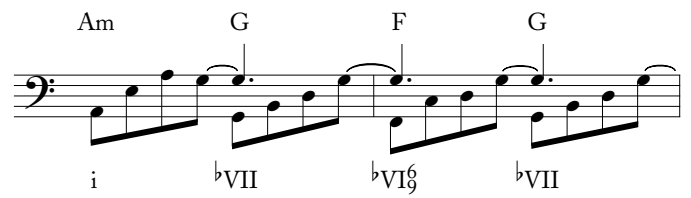

eXample i3. Neighboring Aeolian: $i-b V I I-(b V I)-b V I I$; Blue Öyster Cult, "Don't Fear the Reaper," beginning of verse

melody, however, is passing: the lead vocals are mostly in parallel tenths with the bass, the backing vocals in passing contrary motion. In another context, the chorus of Aerosmith's "Dream On," the chords are neither texturally nor rhythmically differentiated by the instruments, but the vocal melody is consistently more consonant with bVI than with bVII.

Passing Aeolian progressions resemble descending tetrachords that stop short of a descent to $\mathrm{V}$, substituting the modal dominant bVII, which connects the tonic and the submediant in both directions. In the climactic final section of Led Zeppelin's iconic "Stairway to Heaven" (Example 14), the chord hierarchy is established both harmonically and melodically: bVI receives greater durational and rhythmic emphasis in all instruments than does bVII, and serves as the phrase goal of the vocal line. The tonic is prolonged through melodic emphasis on notes of the tonic triad in "Stairway to Heaven," the Rolling Stones' "Gimme Shelter" (albeit with blue thirds and fifths), and Bob Dylan's "All Along the Watchtower"; melodic accentuation of the tonic triad is clearer still in Jimi Hendrix's version of the latter. In Kansas's "Carry On Wayward Son," the dominant pedal in the piano 


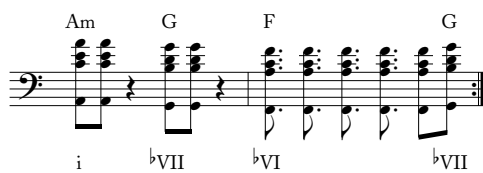

example I4. Passing Aeolian: $i-(b V I I)-b V I-(b V I I)$; Led Zeppelin, "Stairway to Heaven," final section

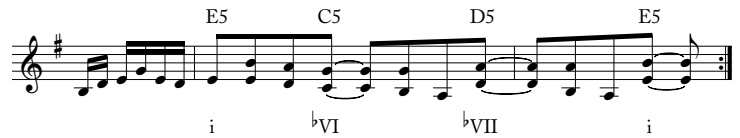

EXAMPLe i5. Circular Aeolian: $i-b V I-b V I I-I$; Derek and the Dominos, "Layla," chorus (original 1970 version; note that the sounding pitch of this recording is closer to $E^{b}$ minor than $E$ minor)

creates added-note dissonances on the non-tonic chords. The relative status of these chords is clarified by the harmonic rhythm in the stop-time verse following the solo, in which the durations of I and bVI are extended and that of $b \mathrm{VII}$ is truncated.

Circular Aeolian progressions typically ascend by step from bVI to I, as in the chorus of Derek and the Dominoes' "Layla." The rhythm guitar part is shown in Example 15; the bass states the chord roots, while the lead guitar plays in a high register in contrary motion with the bass. The vocal line enhances the linear connection between $b \mathrm{VII}$ and $\mathrm{i}$ through stepwise approaches to each member of the tonic triad: $\hat{4}-\hat{5}, \hat{4}-\hat{3}$, then $b \hat{7}-\hat{1}$. The selfcontained nature of the circular progression is underlined by the distant key relationship between the verse and chorus, which are in minor keys a semitone apart.

Like the uppermost voice of the "Layla" riff, the chorus melody of Patti Smith's "Because the Night" is in parallel fifths with the bass and, as in "Dream On," the chorus resolves an oscillating $\mathrm{V}^{769}$ at the end of the verse. Unlike most of the previous examples, the chorus pattern of Grand Funk Railroad's "We're an American Band" consists of five chords (Example 16), creating an asymmetrical harmonic rhythm. The increased rate of

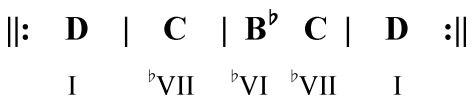

eXample i6. Circular Aeolian: I-bVII-(bVI)-bVII-I; Grand Funk Railroad, "We're an American Band," chorus chord pattern

$$
\begin{aligned}
& \left|C^{5}\right| D^{5}\left|E^{5}\right| E^{5} \mid \\
& \left|C^{7 \sharp 9}\right| D^{7}\left|E^{5}\right| E^{5} \mid \\
& { }^{b} \mathrm{VI} \quad{ }^{b} \mathrm{VII} \quad \mathrm{I}
\end{aligned}
$$

eXample i7. Closed Aeolian:bVI-bVII-I; Jimi Hendrix, "Voodoo Child (Slight Return)," refrain chord pattern

harmonic change in the third measure supports the sentence structure of the melody, which fragments at this point.

Because they begin off-tonic, both examples of closed Aeolian progressions are cadential phrases that conclude the verse. The refrain of Jimi Hendrix's "Voodoo Child (Slight Return)," shown in Example 17, states and then repeats the pattern with chord extensions, but sevenths and raised ninths are typical of blues-based idioms in general and Hendrix's idiolect in particular, and do not alter the essential harmonic function.

The verse progression of Bon Jovi's "Livin' on a Prayer" (Example 18) is circular rather than closed, although because of the extended initial tonic, the last four measures have a stronger cadential effect than that heard in the other circular examples. In the pre-chorus, this pattern is compressed into a closed pattern marked by syncopated harmonic rhythm.

Just as the circular Aeolian progression with initial tonic omitted becomes a closed progression, with final tonic omitted it becomes an open progression. Considered in a larger structural context, in an open progression the final tonic is postponed until the beginning of the next phrase. In all the examples of closed progressions the initial tonic is twice as long as the following two chords, which clarifies its hierarchical status and, after the first instance, provides a sense of resolution. In Alice Cooper's "I'm Eighteen" (Example 19), at the end of the first two choruses the $b \mathrm{VI} \rightarrow \mathrm{VII}$ ascent is expanded to $\mathrm{IV}-\mathrm{V} \rightarrow \mathrm{VI} \rightarrow \mathrm{VII}$, creating an

\section{Verse: $\quad\left\|: \underset{i}{\mathbf{E m}}|\mathbf{E m}| \mathbf{E m}|\mathbf{E m}| \underset{{ }^{b} V I}{C}\left|\underset{b^{b} V I}{D}\right| \underset{i}{\mathbf{E m}} \mid \mathbf{E m}:\right\|$

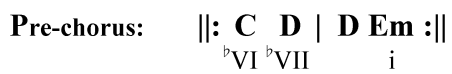

eXample i8. Circular/Closed Aeolian: (i)-bVI-bVII-I; Bon Jovi, "Livin' on a Prayer," verse and pre-chorus chord patterns

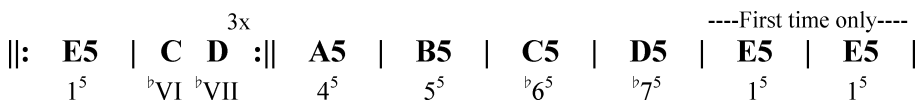

eXample 19. Open Aeolian: i-bVI-bVII; Alice Cooper, "I'm Eighteen," chorus chord pattern 
even stronger drive to the tonic. This extended ascent necessitates two extra bars of tonic following the first chorus, which regularizes the hypermeter to a group of six two-bar units rather than five. In the Scorpions' "No One Like You," the repeated open Aeolian pattern prepares a dominant that arrives at the end of the chorus (not shown).

This survey of double-plagal and Aeolian progressions in rock music reveals that they behave quite similarly. Although their pitch syntax is not diatonically tonal, in many cases these two characteristic chord patterns express traditional tonal functions such as tonic prolongation and dominant preparation, both of which are often accomplished through elaboration of the tonic by subdominant harmony and cadential resolution. As has been demonstrated, hierarchical importance within the progressions can be implied by pitch relations, but is frequently defined or reinforced by other elements such as phrase structure, metric and durational emphasis, consonance, contour, and texture. In all pattern types except closed progressions, tonic chords fall on a hypermetric downbeat. Closed and open progressions are three chords long instead of four, so the length of the tonic is normally doubled to preserve a regular 4-bar hypermeter. In closed progressions, the durational emphasis on the tonic also serves to compensate for its lack of metric accentuation. My focus thus far has been on different types of progressions; in the remainder of this essay I will investigate harmonic and phrase function in the context of larger-scale triadic structures.

\section{PENTATONIC-TRIAD STRUCTURES}

In his article "Making Sense of Rock's Tonal Systems," Walter Everett identified a common harmonic scheme original to rock music, consisting of a major triad built on each degree of a minor pentatonic scale. ${ }^{31}$ The uniformity of triad qualities likely derives from the parallel barre chords idiomatic to the guitar, and their root relationships from the basic shapes of nonbarred major chords on the guitar, which comprise a fifth-cycle or pentatonic collection: $\mathrm{E}, \mathrm{A}, \mathrm{D}, \mathrm{G}$, and $\mathrm{C}$. A tonal, rather than technical, influence is the limited possibility of diatonic harmony in the pentatonic collection, which allows for only one major and one minor triad. Finally, the preference for major over diatonic triads may relate to the use of distorted timbres, which render major triads somewhat dissonant, but minor triads significantly more so.

Like the parallel fourths and fifths of power chords, such parallel-triadic structures blur the distinction between melody and harmony. Everett has argued that pentatonic-triad harmony, because of its parallelisms, represents a non-functional acoustical doubling or tripling of a single melodic line:

\footnotetext{
the chords ... are not functionally related, and do not normally lead to each other in progressions-even though both the first and fifth scale
}

3I Everett (2004, §19-22). This construct exemplifies Richard Bobbitt's category of "mixed-diatonic harmony," in which chord roots conform to a particular scale but the chord structures built on those roots do not, a trait which he describes as a "basic characteristic of rock harmony" (1976, 16-17 and 45). degrees are represented as roots - any more than melodic events in the minor-pentatonic scale are expected to resolve in any particular way. ${ }^{32}$

The tonic of a pentatonic scale may not be clearly defined because of its near-symmetric structure and preponderance of embedded [025] subsets. ${ }^{33}$ Against a harmonic background in rock and blues, however, the pentatonic scale often expresses a melodic hierarchy privileging $\hat{1}$ and $\hat{5}$, especially in vocal melodies. ${ }^{34}$ Some very common melodic figurations in blues-rock are constructed from minor thirds above the tonic and dominant plus major seconds above or below the thirds: the "axe-fall" progressions $\hat{4}-\overrightarrow{3}-\hat{1}$ and $\hat{1}-\hat{7}-\hat{5}$, and various configurations of the upperthird and lower-second neighbor notes $\{b \hat{3}, \hat{1}, b \hat{7}\}$ and $\{b \hat{7}, \hat{5}, \hat{4}\}$.

To Everett's definition I add that, in theory, the tonic may be assigned to any degree of the pentatonic scale, resulting in five possible rotations. ${ }^{35}$ The traditional ordering of pentatonic rotations begins with the major pentatonic as the first mode, and ends with the minor pentatonic as the fifth. However, the minor pentatonic is fundamental to the rock-guitar idiom: it is typically the first scale a guitarist learns, because it can be played in an easily-mastered box pattern on the fretboard, and is often the basis of extended improvisations. In the key of $\mathrm{E}$, each note of the minor pentatonic scale is an open string. It is also the most symmetrical ordering of this interval series. For these reasons, I have assigned it the first position in the rotation.

Example 20 shows the rotations of the minor pentatonic scale, their melodic scale degrees, triad-doubled harmonies, and the resulting cross-relations. Pentatonic harmony can be voiced with several different types of structures: complete triads, creating cross-relations, or power chords or stacked fourths, minimizing the cross-relations. These three chordal syntaxes are characteristic of different timbres and genres. Complete triads are most typical in acoustic timbres; power chords in electric timbres (especially those with distortion such as hard rock and heavy metal); and quartal harmonies, a conventional jazz pentatonic voicing, in keyboard-based textures. Chris McDonald has observed that the chromatic thirds and other cross-relations-in his terminology, "modal subversions" - characteristic of grunge and other alternative genres may derive from the adoption of the modally ambiguous power chord as a favored sonority. ${ }^{36}$

In Example 21, these pentatonic-triad rotations are mapped onto the cycle of fifths. The lines across the circle connect the

32 Everett $(2004, \S 19)$.

33 Four instances of [025] are embedded in the pentatonic scale: $\{\hat{1}, b \hat{3}, \hat{4}\},\{\hat{4}, \hat{5}$, $b \hat{7}\},\{\hat{5}, b \hat{7}, \hat{1}\}$, and $\{b \hat{7}, \hat{1}, b \hat{3}\}$. Everett refers to this set class as the "blues trichord" (2009, 169ff.).

34 This contention is supported by research on melodic pentatonic structures in the blues, a genre that has retained its considerable influence on pentatonic usage in rock. In a study of early blues melodies, Jeff Todd Titon concluded that, while any note might be used in a blues melody, the tonic and dominant act as stable referential pitches (1994, 154-59). Peter van der Merwe has explored melodic minor-third gestures in vernacular music, and posited a "ladder of thirds" underlying many blues and folk melodies that allows for thirds above and below the tonic and dominant degrees: $\hat{6}-\hat{1} \rightarrow \hat{3}-\hat{5} \rightarrow \hat{7}(1989,120-25)$.

35 Chord structures deriving from these triad-doubled modes are readily found in rock music from the mid-1960s onwards.

36 McDonald (2000, 356-58). 


\begin{tabular}{|c|c|c|c|}
\hline$\underline{\text { Rotation }}$ & $\underline{\text { Scale degrees }}$ & $\underline{\text { Triads }}$ & $\underline{\text { Cross-relatior }}$ \\
\hline Pentatonic 1 (minor) & $\begin{array}{lllll}1^{b} & 3 & 4 & 5^{b} & 7\end{array}$ & $\mathrm{I}^{b} \mathrm{III}$ IV V ${ }^{b} \mathrm{VII}$ & ${ }^{b} 3 / /^{b} 3,{ }^{b} 7 /{ }^{\natural} 7$ \\
\hline Pentatonic 2 (major) & $\begin{array}{lllll}1 & 2 & 3 & 5 & 6\end{array}$ & $\begin{array}{lllll}\text { I } & \text { II } & \text { III } & \text { V } & \text { VI }\end{array}$ & $1 / /^{\#} 1,5 / /^{\#}$ \\
\hline Pentatonic 3 & $\begin{array}{lllll}1 & 2 & 4 & 5 & { }^{b}\end{array}$ & I $\quad$ II $\quad$ IV $\quad{ }^{b}$ VII & $4 /{ }^{\#} 4,{ }^{b} 7 /{ }^{\natural} 7$ \\
\hline Pentatonic 4 & 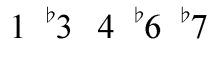 & $I^{b} I I I I V{ }^{b} V I{ }^{b} V I I$ & ${ }^{b} 3 / /^{\mathrm{b}} 3,{ }^{\mathrm{b}} 6 /{ }^{\mathrm{b}} 6$ \\
\hline Pentatonic 5 & $\begin{array}{lllll}1 & 2 & 4 & 5 & 6\end{array}$ & $\begin{array}{lllll}\text { I } & \text { II } & \text { IV } & \text { V } & \text { VI }\end{array}$ & $1 /{ }^{\#} 1,4 /{ }^{\#} 4$ \\
\hline
\end{tabular}

EXAMPLE 20. Pentatonic-triad structures

bounding harmonies for each pentatonic collection, while the harmonies at the bottom of the circle occur only in larger triaddoubled structures, discussed below. Reading the diagram clockwise reflects the relative frequency of triadic pentatonic structures in rock-compositional practice. The most common triadic structure is Pentatonic 4, which comprises the tonic and the four adjacent chords on the flat side, and the next most common is Pentatonic 1 . Pentatonic 4 can be realized as a descending-fourth chain from bVI to the tonic; Pentatonic 1 as a chain from 'III to the dominant. Examples of songs or sections constructed from these chords, or subsets thereof, are readily found in the classic-rock repertory. It seems likely that Pentatonic-triad 4 is prevalent in rock music because it includes $b \hat{7}$ and its cross-relations involve scale-degrees $\hat{3}$ and $\hat{b}$, a pattern that closely models the pitch syntaxes of both the blues and major/minor mixture. The least common structures are Pentatonic-triad 2 and 5, consisting largely of sharp-side triads, of which I could find no examples. It is probable that these two structures are rare because their inherent cross-relations destabilize the primary scale-degrees $\hat{1}, \hat{4}$, and $\hat{5}$; thus the sharp-side

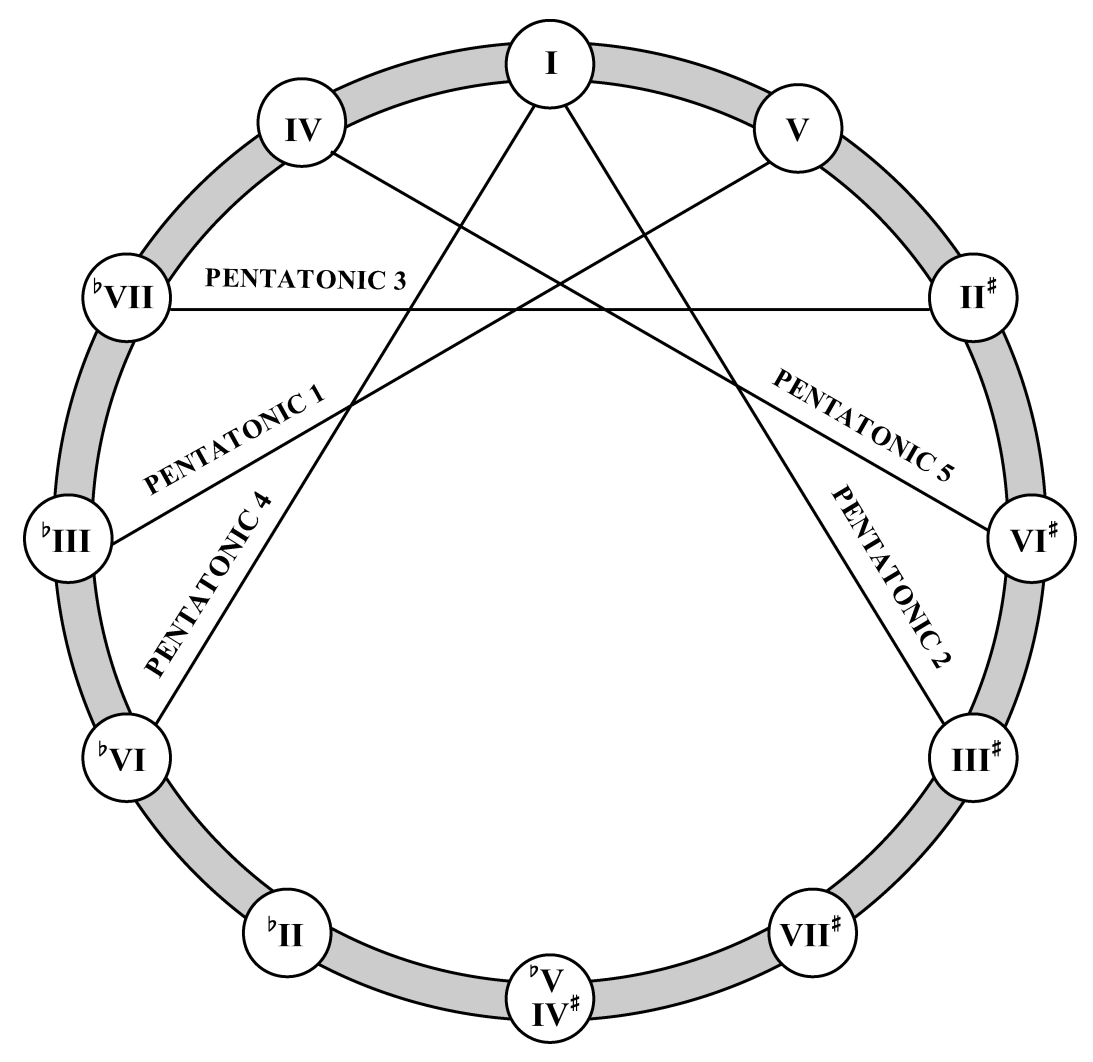

example 21. Pentatonic-triad structures mapped onto fifth-cycle 
triads featuring these degrees are most likely to function as secondary dominants in another key. Since the flat-side triads create cross-relations on secondary scale degrees, they are readily interpreted as modal inflections or mixtures as well as applied dominants or subdominants.

Because the double-plagal progression comprises a fourthprogression above the tonic, it is a subset of three different pentatonic-triad structures: Pentatonic 4, 1, and 3 . In contrast, the Aeolian progression is a subset of Pentatonic 4 alone, the only rotation that includes $b V I$. Pentatonic 1 and 4 include the chords that realize the tonic axe-fall progression, IV-IIII-I. Because of its explicitly pentatonic structure, a brief discussion of this progression is germane to the subject at hand. However, a full exploration of the axe-fall in rock music is too large and complex a topic to be treated here, as the pattern is not original to rock, but requires consideration of its melodic roots in the blues, its melodic and harmonic manifestations in rock, and its numerous variants. For example, the tonic axe-fall chords occur in ascending order (I-III-IV, a reverse axe-fall) in the verses of the Beatles' "Back in the U.S.S.R." (1968) and J. J. Cale's "After Midnight" (1966), and the opening of Deep Purple's "Smoke on the Water" (1972), a rotated version (bIII-IV-I) in the verse of Steppenwolf's "Born to be Wild" (1968), and a circular version (I-bIII-IV $-\mathrm{I})$ that begins the chorus of the Beatles' "Sgt. Pepper's Lonely Hearts Club Band" (1967). The Lydianinflected inversion of this progression, I-II-IV-I, is a subset of both Pentatonic 3 and 5, and comprises the verse patterns of the Beatles' "Eight Days a Week" (1964) and Queen's "A Kind of Magic" (1986). The dominant axe-fall chords I- $\rightarrow$ VII-V, which are subsets of Pentatonic 1 and 3, are used in the chorus of the Pretenders' "Middle of the Road" (1984), briefly discussed below. The dominant axe-fall also occurs in reverse and rotated forms, and the riff of Led Zeppelin's "Misty Mountain Hop" (1971) is an inverted version, $\hat{5}-\hat{4}-\hat{2}$. Thus, like its blues-melodic antecedents, the axe-fall chord pattern occurs both above and below the tonic and dominant, which serve either as goals or points of departure. The Pentatonic 4 structure allows for a subdominant axe-fall, bVII- $\rightarrow$ VI-IV, but I have as yet found no convincing examples of this progression. Nonetheless, there is an unsurprising correlation between emblematic chord patterns in rock music and the prevalence of their pentatonic-triad supersets.

Chord structures deriving from these triad-doubled modes are readily found in rock music from the mid-1960s onwards. Example 22 lists a selection of triadic pentatonic songs and their chord patterns. Verses and choruses are identified by a boxed v or c, section breaks are separated by a slash, and subordinate harmonies are in parentheses. As in the shorter progressions discussed above, chord hierarchies are frequently established through combinations of phrase structure, meter, duration, texture, consonance, and contour, and conventional harmonic and phrase functions can often be ascribed.

Most of the harmonies in the Pentatonic-triad 1 examples are explicitly fourth-related. The refrain of the Beatles' "Me and My Monkey," for instance, begins with an open double-plagal progression that prepares an authentic cadence in which the $\mathrm{V}^{7}-\mathrm{I}$ resolution is accentuated by changes in meter, harmonic rhythm, texture, and timbre. The bridge of the Beatles' "Here Comes the Sun" is a descending-fourth cycle from bIII to V, featuring multiple metric shifts which durationally privilege the tonic despite the dominant's status as goal. The power-chord pattern of AC/DC's "Back in Black" is constructed from double-plagal motions elaborating I, IV, and V, shifting from an open progression in the verse to closed ones in the chorus. The chorus of the Pretenders' "Middle of the Road" is a dominant axe-fall, while in the verse the tonic and subdominant are expanded by lower-neighbor chords.

The lone example of Pentatonic-triad 3, The Kinks' "You Really Got Me," is a large-scale I-II-V progression elaborated with lower-neighbor chords that function as local bVII-I motions. I interpret the song structure as ending on $V$ and employing the classic blues turnaround V-IV-I to regain the initial tonic; the progression can also be parsed as a large-scale IV$\mathrm{V}-\mathrm{I}$, but this analysis is less convincing, as it sets the entire solo in the subdominant and casts the opening oscillation as bIII-IV rather than bVII-I. The Kinks' "All Day and All of the Night" (1964) is a clearer example of a large-scale IV-V-I, in which each harmony is elaborated with pentatonic lower-second and upper-third neighbors. The first pentatonic $1 / 4$ subset, Cream's "Sunshine of Your Love," is a very similar large-scale I-IV-V with lower neighbors. Like "You Really Got Me," "Sunshine of Your Love" ends on V, and could also be construed as arriving on the tonic via a large-scale IV $\rightarrow$ VII-I progression. However, the pedal point and melodic arpeggiation of a dominant seventh (with blue third) in the final section indicate dominant function rather than tonic.

Two of the other Pentatonic 1/4 subsets, The Who's "Love Ain't for Keepin'” and Bon Jovi's "Wanted Dead or Alive," are expanded double-plagal structures. "Love Ain't For Keepin'" follows a closed double-plagal progression-unusual at the beginning of a song-with a subtonic cadence approached from the fourth above ( $(\mathrm{III} \rightarrow \mathrm{VII}-\mathrm{I})$; in this context, $b \mathrm{III}$ takes on predominant function. "Wanted Dead or Alive" answers an open double-plagal progression with a closed one that interpolates bIII between IV and I, as in the tonic axe-fall pattern, an effect reminiscent of a V-IV-I blues turnaround with the non-tonic chords a step lower.

The first two examples of Pentatonic-triad 4 are descendingfourth sequences from $b \mathrm{VI}$ to I. In Jimi Hendrix's recording of "Hey Joe," the tonic is implied in the introduction, and its arrival at the end of the progression is intensified by the leading tone in the bass and conjunct descending motion in the backup vocals. The chorus of Deep Purple's "Hush" is contextualized, and its rapid harmonic motion contrasted, by the tonic pedal under the verses. A shorter descending-fourth sequence, from bIII to I, concludes the verse of ELO's "Don't Bring Me Down," a Pentatonic $1 / 4$ subset. The tonic of Joni Mitchell's "Free Man in Paris" is less clear; it is repeatedly contravened by successions of bIII, bVI, and bVII chords, which suggest I, IV, and V in the 


\begin{tabular}{|c|c|c|}
\hline$\underline{\text { System }}$ & Harmonic pattern & Examples \\
\hline $\begin{array}{l}\text { Pentatonic } 1 \\
\left(1^{b} 345^{b} 7\right)\end{array}$ & 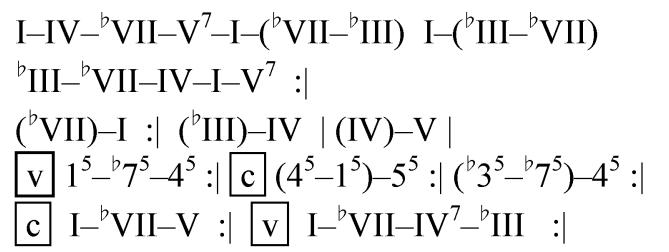 & $\begin{array}{l}\text { Beatles, "Me and My Monkey" (1968), refrain } \\
\text { Beatles, "Here Comes the Sun" (1969), bridge } \\
\text { Mountain, "Mississippi Queen" (1970) } \\
\text { AC/DC, "Back in Black" (1980) } \\
\text { Pretenders, "Middle of the Road" (1984) }\end{array}$ \\
\hline $\begin{array}{l}\text { Pentatonic } 3 \\
\left(\begin{array}{llll}1 & 2 & 4 & 5^{b} 7\end{array}\right)\end{array}$ & $\left({ }^{b} \mathrm{VII}\right)-\mathrm{I}:|(\mathrm{I})-\mathrm{II}:|(\mathrm{IV})-\mathrm{V}: \mid$ & The Kinks, "You Really Got Me" (1964) \\
\hline $\begin{array}{l}\text { Pentatonic } 4 \\
\left(1^{b} 34^{b} 6^{b} 7\right)\end{array}$ & 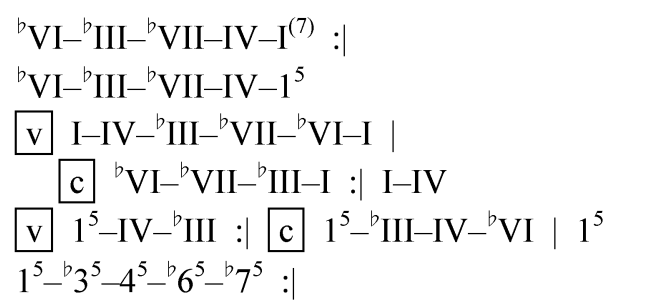 & $\begin{array}{l}\text { Jimi Hendrix, "Hey Joe" (1966) } \\
\text { Deep Purple, "Hush" (1968), chorus } \\
\text { Joni Mitchell, "Free Man in Paris" (1974) } \\
\text { The Knack, "My Sharona" (1979) } \\
\text { Scorpions, "Rock You Like a Hurricane" (1984) }\end{array}$ \\
\hline $\begin{array}{l}\text { Pentatonic } \\
1 / 4 \text { subset } \\
\left(\begin{array}{lll}1^{b} & 4^{b} 7\end{array}\right)\end{array}$ & 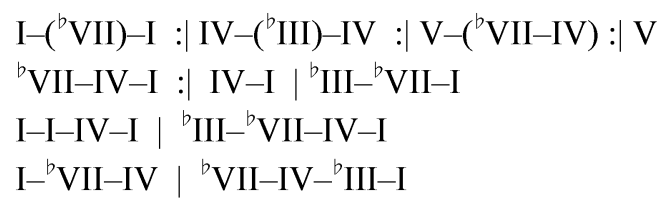 & $\begin{array}{l}\text { Cream, "Sunshine of Your Love" (1967) } \\
\text { The Who, "Love Ain't For Keepin"” (1971) } \\
\text { ELO, "Don’t Bring Me Down" (1979), verse } \\
\text { Bon Jovi, "Wanted Dead or Alive" (1986), verse }\end{array}$ \\
\hline $\begin{array}{l}\text { Pentatonic } \\
4 \text { subsets } \\
\left(1{ }^{b} 34^{b} 6\right) \\
\left(14^{b} 6^{b} 7\right)\end{array}$ & 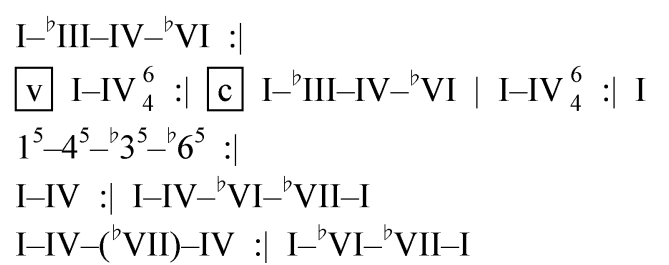 & $\begin{array}{l}\text { Boyce and Hart, "I'm Not Your Steppin' Stone" (1966) } \\
\text { Spencer Davis, "Gimme Some Lovin"” (1966) } \\
\text { Nirvana, "Smells Like Teen Spirit" (1991) } \\
\text { Beatles, "Lady Madonna" (1968), chorus } \\
\text { Queen, "Crazy Little Thing Called Love" (1979), verse }\end{array}$ \\
\hline
\end{tabular}

key of the flat mediant. The harmonic destabilization inherent in this pattern is mirrored by the rhythmic destabilization of the highly syncopated melody. Led Zeppelin's blues-based "Trampled Underfoot" repeats a reverse tonic axe-fall (i-III ${ }^{7}$ $\left.\mathrm{IV}^{7}\right)$, then sequences the interval pattern upward to an Aeolian cadence; the Scorpions' "Rock You Like a Hurricane" is a more concise linear Pentatonic-4 ascent. The Knack's "My Sharona" begins with a rotated tonic axe-fall, and then expands the tonic and subdominant with ascending thirds, from I expanded by bIII to IV expanded by bVI.

The first two examples of Pentatonic 4 subsets, "I'm Not Your Stepping Stone," and "Gimme Some Lovin," have chord patterns similar to that of "My Sharona." It is also possible, however, to hear bIII in these songs as a lower neighbor to IV, and bVI as overshooting an expected V by one scale degree. Nirvana's "Smells Like Teen Spirit" employs the same chord roots in a nonlinear ordering, forming a pair of disjunct ascending fourths that obscure the tonic. The last examples in this category, the Beatles' "Lady Madonna" and Queen's "Crazy Little Thing Called Love," are variants of the 12-bar blues pattern that end with Aeolian cadences.

In rock practice, the most common triad-doubled pentatonic structures are those on the flat side of the tonic, Pentatonic 4 and 1 . The prevalence of these chord collections reflects the modally mixed pitch vocabulary of much classic rock-music. Pentatonic-triad structures provide a background model that encompasses a variety of progression types, including doubleplagal motions and longer cycles of fourths, axe-fall and other pentatonic progressions, and blues patterns with Aeolian turnarounds, as well as some ambiguous examples in which chord function and hierarchy are not clear (such as "Free Man in Paris" and the verse of "Middle of the Road"). The flexible pitch degrees inherent in the sharp-side structures, Pentatonic 2 and 5 , are most likely to function as applied leading tones in a 
system

Aeolian, no $\hat{2}$

Aeolian, no $\hat{3}$

Aeolian, no $\hat{5}$

Aeolian/Dorian, no $\hat{6}$

Aeolian

Phrygian, no $\hat{5}$

Locrian, no ${ }^{b} \hat{2}$ or ${ }^{b} \hat{6}$
$\mathrm{I}^{6}$ II ${ }^{b} \mathrm{III}$ IV $\mathrm{V}{ }^{b} \mathrm{VII}^{6}$

I II ${ }^{b}$ III IV $\mathrm{V}{ }^{b}$ VII

$\underline{\text { harmonies (unordered) }}$

I ${ }^{b}$ III IV V ${ }^{b} \mathrm{VI}{ }^{b} \mathrm{VII}$

I ${ }^{b}$ III IV $^{7} \mathrm{~V}^{7}{ }^{b} \mathrm{VI}^{7}{ }^{b} \mathrm{VII}$

I ${ }^{b}$ III IV $\mathrm{V}{ }^{b} \mathrm{VI}{ }^{b} \mathrm{VII}$

$1^{5}{ }^{b}$ III IV V ${ }^{b} \mathrm{VI}{ }^{b} 7^{5}{ }^{b} \mathrm{VII}$

I ${ }^{b}$ III IV V ${ }^{b} \mathrm{VI}{ }^{b} \mathrm{VII}$

$\begin{array}{llllllll}1^{5} & b^{2} & 3^{5} & 4^{5} & 5^{5} & { }^{b} 6^{5} & { }^{b} & 7^{5}\end{array}$

i I ${ }^{b}$ III IV $\mathrm{V}^{7}{ }^{b} \mathrm{VI}{ }^{b} \mathrm{VII}$

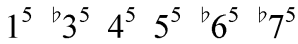

$\begin{array}{lllllll}1^{5} & 2^{5} & 4^{5} & 5^{5} \quad 6^{5} \quad b 7^{5}\end{array}$

$1^{5} 2^{5} \quad{ }^{b} 3^{5} 4^{5}{ }^{b} 6^{5} \quad{ }^{b} 7^{5}$

I II ${ }^{b}$ III IV $\mathrm{V}{ }^{b} \mathrm{VI}{ }^{b} \mathrm{VII}$

I ${ }^{b}$ II ${ }^{b}$ III IV ${ }^{b}$ VI ${ }^{b}$ VII

$\begin{array}{llllllll}1^{5} \quad 2^{5} \quad{ }^{b} 3^{5} & 4^{5} \quad{ }^{b} 6^{5} \quad{ }^{b} 7^{5}\end{array}$

$\begin{array}{llllll}1^{5} & b^{5} & 4^{5} & { }^{b} 5^{5} & b^{b} & 7^{5}\end{array}$ $\underline{\text { examples }}$

The Animals, "I'm Crying” (1964)

The Doors, "Love Me Two Times" (1967)

The Who, "Listening To You" (1969)

The Who, "The Seeker" (1970)

Rolling Stones, "Brown Sugar" (1971)

Golden Earring, "Radar Love" (1973)

Eric Clapton, "Let it Grow" (1974)

Iron Maiden, "The Number of the Beast" (1982)

David Bowie, "Suffragette City" (1972)

Heart, "Barracuda" (1977)

Paul McCartney, "Maybe I'm Amazed" (1970), verse

Alice Cooper, "Elected" (1972), chorus

Beatles, "I am the Walrus" (1967)

The Moody Blues, "Nights in White Satin" (1967)

Rush, "Jacob’s Ladder" (1980), verse

Led Zeppelin, “Immigrant Song” (1970)

EXAMPLE 23. Hexatonic-and heptatonic-triad types

diatonic context, and are rare in the modal-pentatonic repertory under consideration in this study.

\section{HEXATONIC-AND HEPTATONIC-TRIAD STRUCTURES}

The pentatonic-triad structures explored above can be expanded into larger triadic structures that include semitonal root relationships. Example 23 lists a selection of songs with hexatonic-triad structures, and one probably anomalous heptatonic-triad structure. The most widespread of these is Aeolian $-\hat{2}$, which can be considered either a subset of the Aeolian collection or a superset of Pentatonic-triad collections 1 and 4. The next most common hexatonic-triad structure is shifted one chord to the right on the circle of fifths, omitting bVI and adding II: Aeolian/Dorian $-\hat{6}$, a superset of Pentatonic 1 and 3. Phrygian $-\hat{5}$, which occurs much more frequently in heavy metal than in rock, expands Pentatonic 4 by one chord in the flat direction, bII. Two of the Aeolian subsets listed below, Aeolian $-\hat{3}$ and Aeolian $-\hat{5}$, as well as the Locrian subset, cannot be generated from a single fifth-cycle, strongly suggesting that these structures arise from combinations of smaller intervallic sequences-which is indeed how they typically occur in rock practice. Although the harmonic vocabularies of these examples contain only one element more than the pentatonic-triad examples, their chord patterns are too complex to be summarized here and I will not discuss these examples in detail. However, the common triadic progressions identified in the pentatonic structures are prevalent in these hexatonic structures as well: double-plagal, axe-fall, and Aeolian progressions, as well as larger-scale pentatonic and blues patterns.

Although I have presented only a small sampling of songsand, at that, only those with harmonic structures simple enough to be reducible to a few chords - the pentatonic and modal systems they illustrate represent the basis of a significant body of rock music and are a fundamental part of its harmonic and melodic grammar. The surface syntax of these modal and pentatonic systems stands in contrast to a historical and statistical background of major-minor tonality, yet at a deeper level they express many of the underlying principles which have been identified in tonal musics. The triadic structures explored in this study feature chords behaving as tonics, pre-dominants, and dominants, and patterns that accomplish traditional phrase functions such as tonic prolongation, dominant preparation, or cadential arrival. A broader study might delve more deeply into the relationships between blues and rock structures, as well as 
structures deriving from folk modality. Nonetheless, I hope that my assimilation and expansion of some existing tonal theoretical models contributes to a much-needed clearer understanding of triadic modal and pentatonic syntax and function in rock music.

WORKS CITED

Agmon, Eytan. 1995. "Functional Harmony Revisited: A Prototype-Theoretic Approach.” Music Theory Spectrum 17 (2): 196-214.

Biamonte, Nicole. Forthcoming. "Modal Function in Rock and Metal." In Actes colloque d'Analyse musicale de Strasbourg. Ed. Mondher Ayari, Jean-Michel Bardez, and Xavier Hascher. Université de Strasbourg.

Björnberg, Alf. 1984. "There's Something Going On—om eolisk harmonik i nutida rockmusic." Tvärspel: Trettoen artiklar om musik; Festskrift till Jan ling. 371-85. Göteborg: Skrifter från musikvetenskapilga institutionen 9. Göteborg: Musikvetenskapliga institutionen.

- 2007. "On Aeolian Harmony in Contemporary Popular Music." In Critical Essays in Popular Musicology. Ed. Allan F. Moore. 275-82. Aldershot: Ashgate Publishing.

Bobbitt, Richard. 1976. Harmonic Technique in the Rock Idiom: The Theory and Practice of Rock Harmony. Belmont [CA]: Wadsworth Publishing Company.

Brackett, David. 1995. Interpreting Popular Music. Cambridge: Cambridge University Press.

Burns, Gary. 1987. "A Typology of 'Hooks' in Popular Records.” Popular Music 6 (1): 1-20.

Burns, Lori. 2008. "Analytic Methodologies for Rock Music: Harmonic and Voice-Leading Strategies in Tori Amos's 'Crucify.' " In Expression in Pop-Rock Music: Critical and Analytical Essays. 2nd ed. Ed. Walter Everett. 63-92. New York: Routledge Press.

Capuzzo, Guy. 2004. "Neo-Riemannian Theory and the Analysis of Pop-Rock Music." Music Theory Spectrum 26 (2): 177-99.

- 2009. "Sectional Tonality and Sectional Centricity in Rock Music." Music Theory Spectrum 31 (1): 157-74.

Carter, Paul Scott. 2005. "Retrogressive Harmonic Motion as Structural and Stylistic Characteristic of Pop-Rock Music." Ph.D. diss., University of Cincinnati.

Covach, John. 1997. "We Won't Get Fooled Again: Rock Music and Musical Analysis." In Theory Only 13 (1-4): 117-41. Repr. in Keeping Score: Music, Disciplinarity and Culture. Ed. David Schwarz, Anahid Kassabian, and Lawrence Siegel. 75-89. Charlottesville: University of Virginia Press, 1997.

- 2004. "Form in Rock Music: A Primer." In Engaging Music: Essays in Music Analysis. Ed. Deborah Stein. 65-76. New York: Oxford University Press.

Covach, John, and Graeme M. Boone, eds. 1997. Understanding Rock: Essays in Musical Analysis. New York: Oxford University Press.
Doll, Christopher. 2007. "Listening to Rock Harmony." Ph.D. diss., Columbia University.

2009. "Transformation in Rock Harmony: An Explanatory Strategy." Gamut 2 (1). http://dlc.lib.utk.edu/ web/ojs/index.php/first/article/view/99/67 (accessed 8 August 2010).

Everett, Walter. 2004. "Making Sense of Rock's Tonal Systems." Music Theory Online 10.4. http://mto.societymusictheory.org/ issues/mto.04.10.4/mto.04.10.4.w_everett.html (accessed 8 August 2010).

- 2008. "Pitch Down the Middle." In Expression in PopRock Music: Critical and Analytical Essays. 2nd ed. Ed. Walter Everett. 111-74. New York: Routledge Press.

- 2009. The Foundations of Rock: From "Blue Suede Shoes" to "Suite: Judy Blue Eyes." New York: Oxford University Press.

Harrison, Daniel. 1994. Harmonic Function in Chromatic Music: A Renewed Dualist Theory and an Account of its Precedents. Chicago: The University of Chicago Press.

Headlam, Dave. 2002. "Appropriations of Blues and Gospel in Popular Music." In The Cambridge Companion to Blues and Gospel Music. Ed. Allan F. Moore. 158-87. Cambridge: Cambridge University Press.

Kopp, David. 1995. "On the Function of Function." Music Theory Online 1.3. http://mto.societymusictheory.org/issues/ mto.95.1.3/toc.1.3.html (accessed 8 August 2010).

McDonald, Chris. 2000. "Exploring Modal Subversions in Alternative Music.” Popular Music 19 (3): 355-63.

Middleton, Richard. 1990. Studying Popular Music. Milton Keynes [England]: Open University Press.

Moore, Allan F. 1992. "Patterns of Harmony." Popular Music 11 (1): 73-106.

- 1995. "The So-Called 'Flattened Seventh' in Rock." Popular Music 14 (2): 185-201.

- 2001. Rock: The Primary Text_Developing a Musicology of Rock. 2nd ed. Aldershot: Ashgate Publishing.

- 2003. Analyzing Popular Music. Cambridge: Cambridge University Press.

Salzman, Eric, and Michael Sahl. 1977. Making Changes: A Practical Guide to Vernacular Harmony. New York: McGrawHill.

Stephenson, Ken. 2002. What to Listen For in Rock: A Stylistic Analysis. New Haven: Yale University Press.

Tagg, Philip. 1982. "Analysing Popular Music: Theory, Method and Practice." Popular Music 2: 37-67.

- 1990. "Universal Music' and the Case of Death.” In La musica come linguaggio universale: Genesi e storia de un'idea. Ed. Raffaele Pozzi. Historiae musicae cultores 57. Repr. in Critical Quarterly 35 (2): 54-85, 1993.

Temperley, David. 2007. “The Melodic-Harmonic 'Divorce' in Rock." Popular Music 26 (2): 323-42.

Titon, Jeff Todd. 1994. Early Downhome Blues: A Musical and Cultural Analysis. 2nd ed. Urbana: University of Illinois Press. 
Tymockzo, Dmitri. 2003. "Progressions fondamentales, fonctions, degrés: une grammaire de l'harmonie tonale élémentaire." Musurgia 10 (3-4): 35-62. Trans. by the author as "Function Theories: A Statistical Approach" at http://www. music.princeton.edu/ dmitri/ (accessed 8 August 2010).

Van der Merwe, Peter. 1989. Origins of the Popular Style: the Antecedents of 20th-Century Popular Music. Oxford: Clarendon Press.

Music Theory Spectrum, Vol. 32, Issue 2, pp. 95-110, ISSN 0195-6167, electronic ISSN 1533-8339. (C) 2010 by The Society for Music Theory. All rights reserved. Please direct all requests for permission to photocopy or reproduce article content through the University of California Press's Rights and Permissions website, at http://www.ucpressjournals.com/ reprintinfo.asp. DOI: 10.1525/mts.2010.32.2.95 